\title{
Disruption of Arcuate/Paraventricular Nucleus Connections Changes Body Energy Balance and Response to Acute Stress
}

\author{
M. Elizabeth Bell, Seema Bhatnagar, Susan F. Akana, SuJean Choi, and Mary F. Dallman \\ Department of Physiology, University of California, San Francisco, San Francisco, California 94143
}

\begin{abstract}
The mediobasal hypothalamus regulates functions necessary for survival, including body energy balance and adaptation to stress. The purpose of this experiment was to determine the contribution of the arcuate nucleus (ARC) in controlling these two functions by the paraventricular nucleus (PVN). Circular, horizontal cuts $(1.0 \mathrm{~mm}$ radius) were placed immediately above the anterior ARC to sever afferents to the PVN. In shams the knife was lowered to the same coordinates but was not rotated. Food intake and body weight were monitored twice daily, at the beginning and end of the light cycle, for 1 week. On the final day the animals were restrained for $30 \mathrm{~min}$. Lesioned animals had increased food intake in light and dark periods, higher weight gain per day, and more body fat as compared with shams. There was no difference in caloric efficiency. Unlike shams, lesioned rats had no predictable relationship between plasma insulin and leptin.
\end{abstract}

Plasma ACTH was increased at 0 min in lesioned rats but was decreased 15 and 30 min after restraint as compared with shams. There was no difference in plasma corticosterone. Immunostaining revealed that $\alpha$-melanocortin $(\alpha \mathrm{MSH})$ and neuropeptide $Y$ (NPY) accumulated below the cuts, and both were decreased in PVN. Food intake and body weight were correlated negatively to $\alpha \mathrm{MSH}$, but not NPY in PVN. There was no difference in proopiomelanocortin (POMC) mRNA, but NPY mRNA was reduced in the $A R C$ of lesioned animals. We conclude that ARC controls body energy balance in unstressed rats, possibly by $\alpha \mathrm{MSH}$ input to PVN, and that ARC also is necessary for PVN regulation of $\mathrm{ACTH}$.

Key words: $\alpha$-melanocyte-stimulating hormone; neuropeptide Y; CRF; ACTH; restraint; hypothalamus
Central regulation of food intake, energy expenditure, and body weight gain is accomplished by activity in several brain sites; however, both genetic stimulation and lesion experiments suggest that the hypothalamus is critical to central integration of energy balance (Dallman et al., 1995). The medial hypothalamic nuclei have different effects on energy balance; the effects of loss of normal activity in the ventromedial nuclei (VMN) and paraventricular nuclei (PVN) can be distinguished readily from each other (Tokunaga et al., 1986; Parkinson and Weingarten, 1990; Choi and Dallman, 1999; Choi et al., 1999). However, normal activity in both the PVN and arcuate nuclei (ARC) is required for maintenance of normal body weight, and the effects of lesions of these cell groups are difficult to distinguish from each other. Disruption of activity in either the ARC or PVN results in obesity characterized by increased food intake during both light and dark periods of the day and decreased weight loss during the light hours. Moreover, rats with lesions of ARC and PVN still respond to increased foodinduced obesity with increased thermogenesis that is mediated by sympathetic neural stimulation of uncoupling protein in brown adipose tissue (Ghorbani et al., 1997; Choi and Dallman, 1999; Choi et al., 1999).

Endings from cell bodies in the ARC innervate the PVN quite strongly (Sawchenko and Swanson, 1983; Baker and Herkenham, 1995), and at least two peptides derived from proteins synthesized in ARC neurons have been shown to be important in the regulation of energy balance. Neuropeptide Y (NPY) stimulates food intake when it is injected into the PVN and causes obesity when it is

Received Nov. 29, 1999; accepted June 15, 2000

M.E.B. was supported by a fellowship from the National Alliance for Research on Schizophrenia and Depression. This work was supported by National Institutes of Health Grant NIDDK28172. Alan Chu and Liza Soriano provided invaluable technical assistance in these experiments.

Correspondence should be addressed to Dr. Mary F. Dallman, Department of Physiology, University of California, San Francisco, Box 0444, 513 Parnassus Avenue, HSW 747, San Francisco, CA 94143. E-mail: dallman@itsa.ucsf.edu.

Dr. Bhatnagar's present address: Department of Psychology, University of Michigan, Ann Arbor, MI 48109.

Dr. Choi's present address: Department of Psychiatry, University of Pittsburgh, Pittsburgh, PA 15260.

Copyright (C) 2000 Society for Neuroscience $0270-6474 / 00 / 206707-07 \$ 15.00 / 0$ infused into the cerebroventricular system (icv; Stanley et al., 1992). Moreover, rodents with genetic obesity because of a defect in leptin synthesis or reception all exhibit increased prepro-NPY mRNA in ARC (Sanacora et al., 1990) and increased NPY content in PVN (McKibbin et al., 1991), suggesting that at least the increased food intake in these animals may result from hypersecretion of NPY in the PVN. On the other hand, $\alpha$-melanocytestimulating hormone $(\alpha-\mathrm{MSH})$, a peptide derived from the proopiomelanocortin (POMC) precursor that is synthesized in ARC, inhibits food intake when it is injected into the PVN or is infused into icv (Fan et al., 1997; Murphy et al., 1998). Mice with genetic lesions of the melanocortin receptor system are also obese (Huszar et al., 1997), suggesting that this system restrains food intake.

NPY- and POMC-derived peptides also interact with components of the hypothalamo-pituitary-adrenal (HPA) axis. Both peptides innervate corticotropin-releasing factor (CRF) neurons in the PVN (Liposits et al., 1987), suggesting that they can regulate activity in the HPA axis. Acutely, NPY injected into the PVN stimulates adrenocorticotropin (ACTH) secretion (Wahlestedt et al., 1987), and $\alpha \mathrm{MSH}$ infused into icv inhibits it (Calogero et al., 1988; Shalts et al., 1992). Moreover, both CRF and the related neuropeptide urocortin act via CRF receptors in or near the PVN to inhibit food intake (Krahn and Gosnell, 1988; Spina et al., 1996), although the mechanism is not understood completely.

Taken together, the considerable innervation of PVN by axons of ARC cell bodies and the known effects of NPY- and POMCderived peptides on energy balance and function of the HPA axis (probably driven by CRF from PVN) suggest strongly that NPY and $\alpha$-MSH from ARC may regulate both feeding and adrenocortical activity. In this study we altered ARC input to PVN by making small horizontal cuts between the two cell groups to test the effects of a partial removal of ARC-derived peptides from PVN on energy balance and activity in the HPA axis.

\section{MATERIALS AND METHODS}

Animals. Male Sprague Dawley rats from Bantin and Kingman (Fremont, CA) arrived at University of California, San Francisco (UCSF) weighing 220-240 gm and were housed singly in hanging wire cages (lights on, 6:00 A.M.; lights off, 6:00 P.M.). Animals had free access to tap water and chow (Purina Rodent Chow 5008) except for 20 min twice daily while food and 


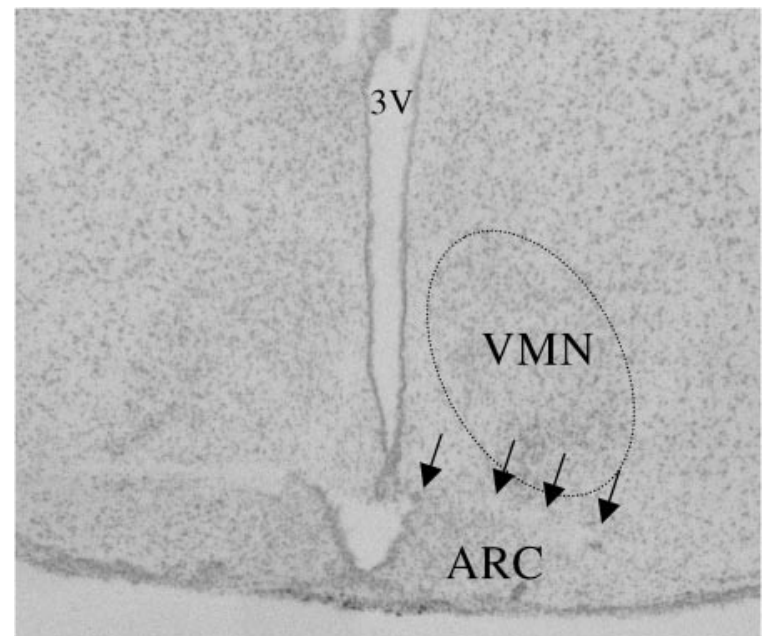

Figure 1. Shown is a Halász knife cut in a brain section stained with cresyl violet. The lesion (arrows) was centered over the anterior half of the arcuate nucleus $(A R C)$ and extended laterally below (but not into) the ventromedial nucleus $(V M N)$.

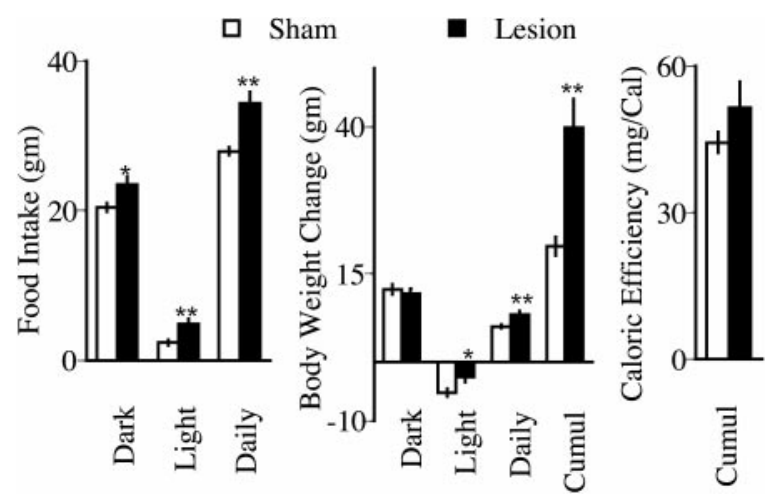

Figure 2. Pattern of food intake and body weight gain after disruption of ARC/PVN connections. Left, Lesioned rats $(n=16)$ ate more food than sham rats $(n=15)$ in dark and in light. Middle, Body weight gain was greater in lesioned rats as compared with shams. The increased weight of lesioned rats as compared with shams is attributable to less weight loss during the light period. The difference in body weight was significant within $24 \mathrm{hr}$ of surgery. Right, Caloric efficiency was the same in lesioned and sham rats. This indicates that lesioned animals have a nutritional obesity unrelated to a decrease in metabolic rate. ${ }^{*} p<0.05 ;{ }^{*} p<0.01$.

body weights were measured (9:00 A.M. and 5:00 P.M.). Food that was eaten was calculated from the weight of offered food, uneaten food, and spilled food. All experimental procedures were approved by the UCSF Committee on Animal Research.

After $2 \mathrm{~d}$ of baseline monitoring the rats were anesthetized with rodent cocktail $(84 \mathrm{mg} / \mathrm{kg}$ of ketamine, $1.7 \mathrm{mg} / \mathrm{kg}$ of xylazine, and $1.7 \mathrm{mg} / \mathrm{kg}$ of acepromazine, i.p.) for stereotaxic surgery. Lesions were made with a Halász knife. The knife blade was $1 \mathrm{~mm}$ long and extended at a right angle from the shaft. The knife was lowered in the midline with the blade pointing anteriorly. When the knife was rotated $360^{\circ}$, cuts $(n=24)$ were placed immediately above the ARC (bregma, $-2.1 \mathrm{~mm}$; anteroposterior, $-10.08 \mathrm{~mm}$; vertical, midline). These coordinates and the length of the blade were chosen in preliminary experiments to maximize the area above the ARC that was cut while sparing the VMN and as many overlying midline structures as possible. In sham-operated rats $(n=15)$ the knife was lowered to the same coordinates but was not rotated. Rats were allowed to recover from anesthesia in a warm environment and were returned to their home cages in the evening. Food intake was measured from 1 to $7 \mathrm{~d}$ after surgery.

At 1 week after surgery the rats were restrained in Plexiglas tubes for 30 min and, after nicking a lateral tail vein with a scalpel, we collected tail blood samples at 0 and $15 \mathrm{~min}$ after the onset of restraint. At $30 \mathrm{~min}$ one-half of the rats $(n=12$ lesioned, 8 sham $)$ were sampled again from the tail and immediately injected with rodent cocktail in preparation for perfusion. Not all samples were of sufficient volume for the desired hormone measurements. After cardiac blood collection the anesthetized rats were perfused with potassium PBS (KPBS), followed by $4 \%$ paraformaldehyde in KPBS. Brains were removed promptly, post-fixed for $5 \mathrm{hr}$ in
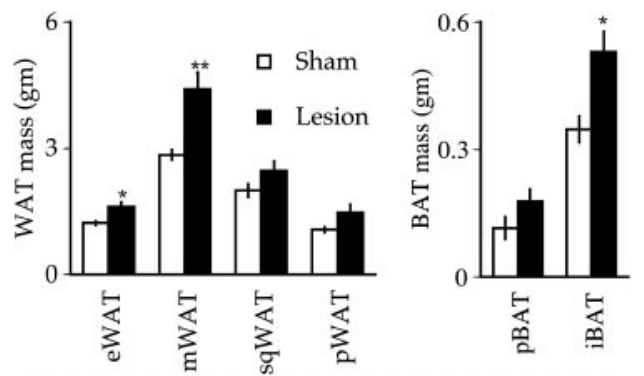

Figure 3. Left, White adipose tissue depots 1 week after disruption of ARC/PVN connections. Lesioned rats $(n=10)$ had significantly increased epididymal $(e W A T ; p=0.015)$ and mesenteric $(m W A T ; p=0.005)$ fat depots as compared with shams $(n=7)$. Although there was no significant difference between subcutaneous ( $s q W A T)$ or perirenal ( $p W A T)$ fat depots in the two groups, there was an overall trend of increased WAT in lesioned animals as compared with shams. Right, Brown adipose tissue 1 week after disruption of ARC/PVN connections. Lesioned rats had a significantly greater interscapular BAT ( $i B A T ; p=0.011$ ) weight as compared with shams. There was no change in $\mathrm{UCP} / \mathrm{mg}$ of $\mathrm{BAT}$ or $\mathrm{UCP} / \mathrm{depot}$ as a result of disrupting the ARC/PVN connections (data not shown). ${ }^{*} p<0.05 ;{ }^{* *} p<0.01$.

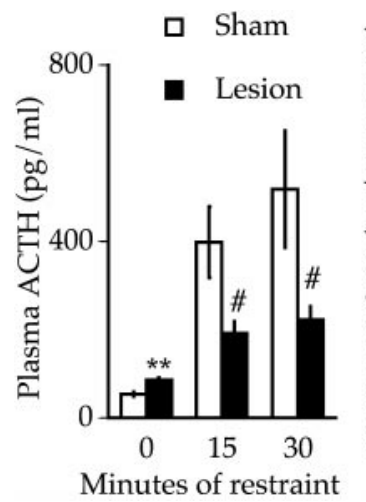

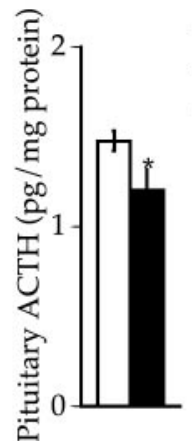

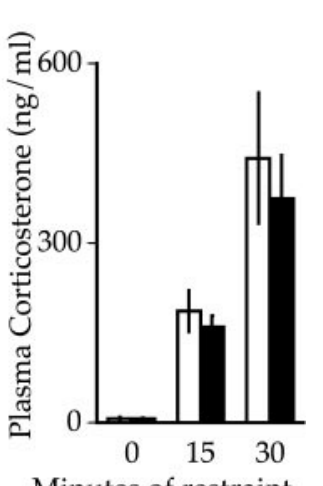

Minutes of restraint
Figure 4. Plasma ACTH and corticosterone $7 \mathrm{~d}$ after disruption of the ARC/PVN connections. Left, Plasma ACTH levels 0,15 , and 30 min after the onset of restraint stress. Lesioned animals $(n=10)$ had higher basal ACTH levels than shams $(n=7)$, but they secreted less ACTH in response to restraint stress. Middle, Pituitary ACTH levels were decreased in lesioned animals as compared with shams. Right, Corticosterone levels were similar in lesioned $(n=14)$ animals as compared with shams $(n=15)$ throughout the restraint stress. ${ }^{\#} p=0.06 ;{ }^{*} p<0.05 ;{ }^{* *} p<0.01$.

$4 \%$ paraformaldehyde in KPBS, transferred to $30 \%$ sucrose (DEPCtreated) for $24 \mathrm{hr}$, sliced in a one in six series on a sliding microtome in 20 $\mu \mathrm{m}$ sections, and stored in antifreeze $\left(5 \mathrm{mg} / \mathrm{ml}\right.$ of heparin, $2 \mathrm{mM} \mathrm{Na}_{2} \mathrm{HPO}_{4}$, $6 \mathrm{mM} \mathrm{NaH} 2 \mathrm{PO}_{4}, 20 \% \mathrm{v} / \mathrm{v}$ glycerol, and $30 \% \mathrm{v} / \mathrm{v}$ ethylene glycol) at $-20^{\circ} \mathrm{C}$ until immunostaining.

The remaining animals were decapitated $30 \mathrm{~min}$ after the onset of restraint stress (10 lesioned, 7 sham); trunk blood, brains, pituitaries, thymuses, adrenals, and white adipose tissue depots were collected. Brains were coated immediately in cryoprotectant (OCT) and frozen in a dry

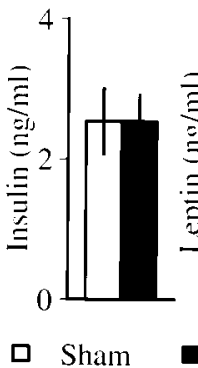

口 Sham

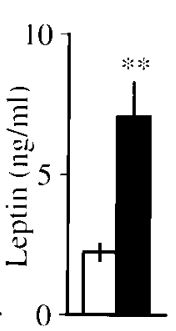

Lesion

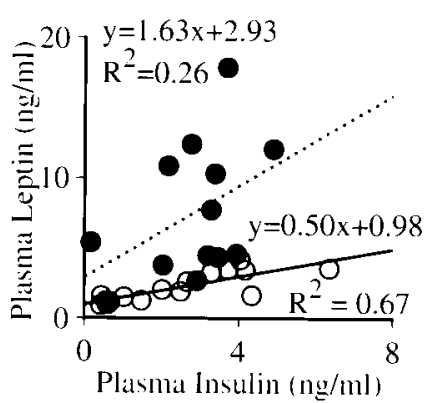

Plasma Insulin (ng/ml)
Figure 5. Plasma insulin and leptin (lesioned, $n=13$; sham, $n=15$ ). Left, Plasma insulin levels were similar between the two groups. Middle, Plasma leptin levels were increased in lesioned animals as compared with shams $(p=0.001)$. Right, Plasma insulin and leptin were highly correlated in shams, but insulin did not predict leptin levels in lesioned animals. Open symbols, Sham rats; filled symbols, lesioned rats. ${ }^{* *} p<0.01$. 

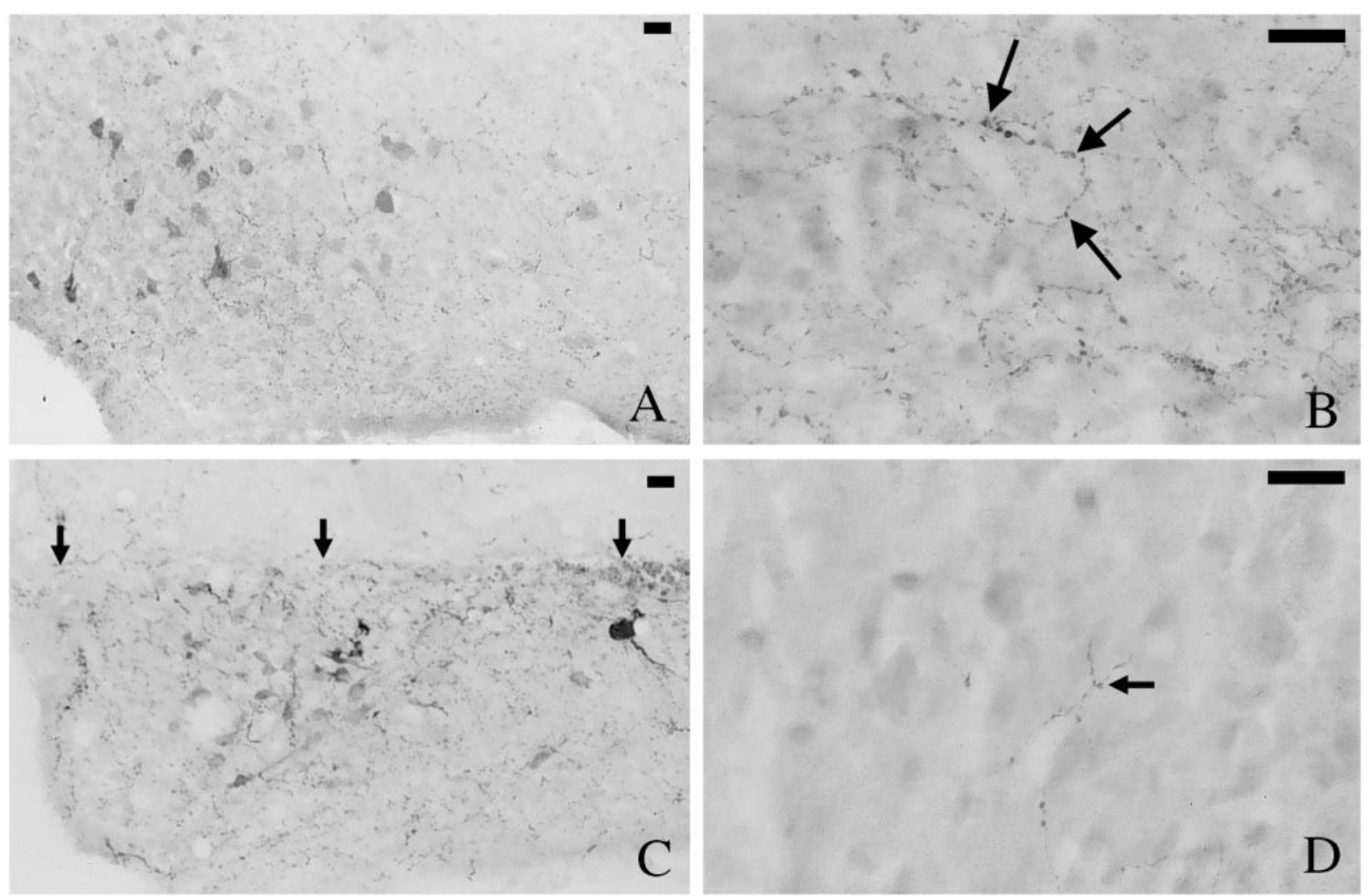

Figure 6. Immunostaining for $\alpha \mathrm{MSH}$ in the ventral hypothalamus. Top, Sham rat; bottom, lesioned rat. Positive immunostaining was defined as $5 \times$ above background. $A, C$, Arcuate nuclei, 200×. $\alpha \mathrm{MSH}$ immunostaining was evident in ARC neurons in both animals and in small varicosities in linear arrangements between the PVN and ARC in the sham rat $(A)$. A dense collection of $\alpha \mathrm{MSH}$-positive varicosities was found immediately ventral to the lesion scar in the lesioned rat $(C$, arrows $) . B, D, \mathrm{PVN}, 630 \times . \alpha \mathrm{MSH}$-positive fibers and varicosities were prominent in the PVN of the sham rat $(B$, arrows $)$ but were rare in lesioned rats $(D$, arrow $)$. Captured images were thresholded, and the number of positively stained varicosities [5-20 pixels $\left(4.8-19 \mu \mathrm{m}^{2}\right)$ in size] was summed for each section in each animal. Scale bar, $50 \mu \mathrm{m}$ in all panels.

ice/ethanol $\left(-56^{\circ} \mathrm{C}\right)$ bath before transfer to a $-80^{\circ} \mathrm{C}$ freezer; then later they were cut into $20 \mu \mathrm{m}$ sections with a cryostat $\left(-16^{\circ} \mathrm{C}\right)$ in a one in five series, dried, and stored at $-80^{\circ} \mathrm{C}$ until in situ hybridization analysis. Pituitary glands were frozen immediately. Subcutaneous, mesenteric, perirenal, and epididymal white adipose tissues (WATs) and interscapular and perirenal brown adipose tissues (BATs), thymuses, and adrenals were cleaned and weighed. Adrenal weight and corticosterone content are good measures of previous ACTH secretion, and thymus weight is sensitive to integrated corticosterone secretion in previous days. BATs and adrenals were frozen and stored at $-20^{\circ} \mathrm{C}$ until they were analyzed for uncoupling protein (UCP) and corticosterone content, respectively.

Radioimmunoassays. Plasma ACTH (interassay CV: 0.18 low, 0.13 high; intrassay $\mathrm{CV}, 0.15$ ) and corticosterone (interassay $\mathrm{CV}$ : 0.15 low, 0.15 high; intrassay $\mathrm{CV}, 0.07$ ) concentrations and uncoupling protein (UCP; interassay CV: 0.15 low, 0.13 high) content in brown adipose tissue were determined as previously described (Strack et al., 1995; Choi and Dallman, 1999; Choi et al., 1999). When there was insufficient plasma for both $\mathrm{ACTH}$ and corticosterone assays, corticosterone was determined. Reagents for the UCP assay were generously provided by Dr. Jean HimmsHagen (University of Ottawa, Ontario, Canada). Pituitaries were homogenized in $1 \mathrm{ml}$ of $0.1 \mathrm{~N} \mathrm{HCl}$, and adrenals were homogenized in $5 \mathrm{ml}$ of buffer as previously described (Wilkinson et al., 1981). All comparisons were made between samples run in a single assay (e.g., all pituitaries in a single ACTH assay). Protein content of pituitary (1:10 dilution), adrenal (1:5 dilution), and brown adipose tissue homogenates was determined by a protein dye assay (Bio-Rad, Hercules, CA); absorbance was measured on a microplate reader (Tecan, Research Triangle Park, NC).

Plasma leptin (interassay CV: 0.13 low, 0.13 high; intrassay CV, 0.05) and insulin (interassay CV: 0.08 low, 0.12 high) levels were determined by radioimmunoassay as previously described (Strack et al., 1997; Choi and Dallman, 1999; Choi et al., 1999).

Histochemistry. Lesions were confirmed by cresyl violet staining in lesioned and sham animals (Fig. 1). Lesions were considered acceptable when cuts were below the VMN and above or involving only the lateral extent of ARC [0.5 mm left and right of midline in at least three consecutive sections $(360-600 \mu \mathrm{m})]$. Rats were eliminated from this study when the cuts were high enough to involve the ventromedial (VMN) or dorsomedial (DMN) hypothalamic nuclei, so low that the lateral ARC extended above the cut in all sections, or when tissue sections were not of sufficient quality to confirm a complete lesion.

Fixed brains were cut on a sliding microtome in a one in six series of 20 $\mu \mathrm{m}$ sections. One series was stained with cresyl violet to evaluate lesion morphology and reveal neuroanatomy. Immunostaining for $\alpha \mathrm{MSH}$ and NPY was performed in perfusion-fixed brain tissue at room temperature except where indicated. Sections were washed four times for $15 \mathrm{~min}$ in PBS, blocked in 10\% normal goat serum (NGS) for $1 \mathrm{hr}$, and then washed three times for 10 min in PBS before incubation with primary antibody at $4^{\circ} \mathrm{C}$ [anti- $\alpha$ MSH 1:2000, 3 d (Advanced Chemtech, Louisville, KY); antiNPY provided by Dr. John Walsh (CURE RIA Laboratory, Los Angeles, CA) $1: 200,1 \mathrm{~d})$ in $3 \%$ NGS and $1 \%$ BSA in PBS with $0.001 \%$ sodium azide]. Sections were washed six times for $10 \mathrm{~min}$ in PBS and incubated with biotinylated goat anti-rabbit antibody (Vector Laboratories, Burlingame, CA) diluted 1:400 in 3\% NGS in PBS for $2 \mathrm{hr}$. Then the tissue was washed four times for $10 \mathrm{~min}$ in PBS and incubated with avidin-biotin complex (ABC Elite kit, Vector) for $1 \mathrm{hr}$. After three $5 \mathrm{~min}$ washings in PBS the sections were visualized by DAB reaction $(0.5 \mathrm{mg} / \mathrm{ml}$; Sigma, St. Louis, MO) in $0.05 \mathrm{~m}$ Tris, $\mathrm{pH}$ 7.6. Then brain sections were mounted and coverslipped for image analysis. Images were captured by using a microscope (Leica DMRB) equipped with a video camera (Optronics 3 CCD) feeding into a Scion LG-3 frame-grabber card (Scion, Frederick, MD); then the images were analyzed (National Institutes of Health Image 1.61) on a PowerMacintosh 7100. Positive immunostaining was defined as $5 \times$ above background. Immunostaining was evident in ARC neurons and in small particles in linear arrangements between the PVN and ARC. We interpreted the latter as varicosities in axons originating from immunopositive neurons. The morphology of knife cuts over ARC was shown clearly by $\alpha \mathrm{MSH}$ staining because of the large numbers of $\alpha \mathrm{MSH}$-positive varicosities immediately ventral to the cut; thus both $\alpha \mathrm{MSH}-$ and cresyl violet-stained ARC sections were used to assess the extent of lesions. Captured images were thresholded, and the number of positively stained varicosities [5-20 pixels $\left(4.8-19 \mu \mathrm{m}^{2}\right)$ in size] in PVN was counted in a total of four $100 \times$ fields (see Fig. 6) and summed for each section in each animal for $\alpha \mathrm{MSH}$ and for NPY. In situ hybridization analyses for NPY and POMC transcripts in ARC and for CRF transcripts in PVN were performed on frozen brains by using the same techniques as previously described (Dallman et al., 1999). A one in ten series of $20 \mu \mathrm{m}$ sections was stained with cresyl violet, and a sequential one in five series of tissue was incubated with radiolabeled ribonucleic acid probes complementary to mRNAs for CRF, POMC, and NPY. In analyzing PVN CRH hybridization, we analyzed four sections spanning the midportion of the nucleus for each animal, representing an anterior-posterior distance of $0.4 \mathrm{~mm}$ (breg$\mathrm{ma}-1.8$ to $2.1 \mathrm{~mm}$ ). NPY and POMC hybridization in ARC included six 
sections per probe, with two sections each representing anterior (bregma $-2.8 \mathrm{~mm}$ ), mid (at the level of the DMN; bregma $-3.3 \mathrm{~mm}$ ), and caudal ARC (bregma $-3.8 \mathrm{~mm}$ ). For each probe a trapezoidal outline was made that encompassed both sides of the nucleus under study at a given anteriorposterior position. The outline and its contents were scanned from x-ray film, the background was subtracted, and repeated measures analysis was performed on the optical densities in the four (CRF) or six sections (NPY and POMC).

Statistical analysis. All comparisons were made by ANOVA, corrected when appropriate for repeated measures and Tukey-Kramer post hoc test. Simple regression analyses also were performed when appropriate. All statistical determinations were done with a Statview 4.0 program.

\section{RESULTS}

Seven lesioned rats were removed from the experiment because they did not meet the criteria for a complete and accurate lesion. Two lesioned rats were eliminated from the study because of poor weight gain and lethargy. Data were used in metabolic and endocrine analyses from two sham animals from which the brains were lost in processing steps.

\section{Energy balance}

Food intake was the same in lesioned and sham animals before surgery, but was increased significantly and consistently in lesioned animals as compared with shams after surgery $(p=0.005$, overall effect $)$ in both the dark $(p=0.016)$ and light $(p=0.002)$ periods of the day ( $p<0.001$; Fig. 2, left $)$. The increase in daily weight gain $(p=0.002)$ in lesioned rats as compared with shams was attributable to decreased loss of body weight during the light period ( $p=$ 0.031; Fig. 2, middle). The gain in body weight was similar between the groups during the dark period. The net result was a highly significant increase in body weight gain over $7 \mathrm{~d}$ in the lesioned rats. Caloric efficiency (body weight gain/caloric intake, both over the $7 \mathrm{~d}$ of the study) was similar in both groups (Fig. 2, right).

Body fat depots reflected an overall increase in adiposity in lesioned rats as compared with shams; this difference was significant in epididymal and mesenteric WAT depots (Fig. 3, left). Interscapular BAT weight also was increased in lesioned rats as compared with shams (Fig. 3, right), but this was not reflected by an increase in UCP in lesioned rats as compared with shams, either per milligram of BAT (lesioned, $0.715 \pm 0.15 \mu \mathrm{g} / \mathrm{mg}, n=8$; sham, $0.784 \pm 0.23 \mu \mathrm{g} / \mathrm{mg}, n=5$ ) or per BAT depot (lesioned, $354 \pm 63$ $\mu \mathrm{g}$; sham, $283 \pm 88 \mu \mathrm{g})$.

There were no significant differences between thymus (lesioned, $540 \pm 26 \mathrm{mg}, n=10$; sham, $504 \pm 53 \mathrm{mg}, n=7$ ) or adrenal (lesioned, $16 \pm 1 \mathrm{mg}, n=9$; sham, $18 \pm 1 \mathrm{mg}, n=7 ; p=0.17$ ) weights or adrenal corticosterone content (lesioned, $72.3 \pm 9.3 \mathrm{ng} / \mathrm{mg}$ of protein, $n=5$; sham, $63.7 \pm 21.7 \mathrm{ng} / \mathrm{mg}$ of protein, $n=6$ ) in the two groups. Pituitary ACTH content was decreased in lesioned animals $(n=5)$ as compared with shams $(n=6 ; p=0.05$; Fig. 4, middle $)$. Because of a storage problem the pituitary and adrenal tissues were available for only a subset of the decapitated animals.

\section{Plasma hormones}

Plasma ACTH levels differed markedly in lesioned animals as compared with shams. Lesioned rats had higher basal plasma ACTH $(p=0.002)$ but attenuated ACTH responses to restraint (overall effect, $p=0.05$; Fig. 4, left). Plasma corticosterone levels were similar between the two groups at all of the times that were measured (Fig. 4, right). Not surprisingly, given their higher fat weights, lesioned animals had significantly higher plasma leptin as compared with shams ( $p=0.040$; Fig. 5 , middle $)$, but there was no difference between plasma insulin levels in the two groups (Fig. 5, left ). The linear relationship between plasma insulin and leptin was disrupted in lesioned animals $\left(r^{2}=0.26 ; p=0.064\right)$ as compared with shams $\left(r^{2}=0.67 ; p<0.001\right.$; Fig. 5, right $)$.

\section{Histochemistry}

The results from immunocytochemical staining and in situ hybridization are shown in Figures 6 through 10. A dense collection of $\alpha \mathrm{MSH}$ varicosities was found immediately ventral to the lesion scar. At low magnification there was no detectable difference in $\alpha \mathrm{MSH}$ immunostaining in PVN between shams and lesioned rats.
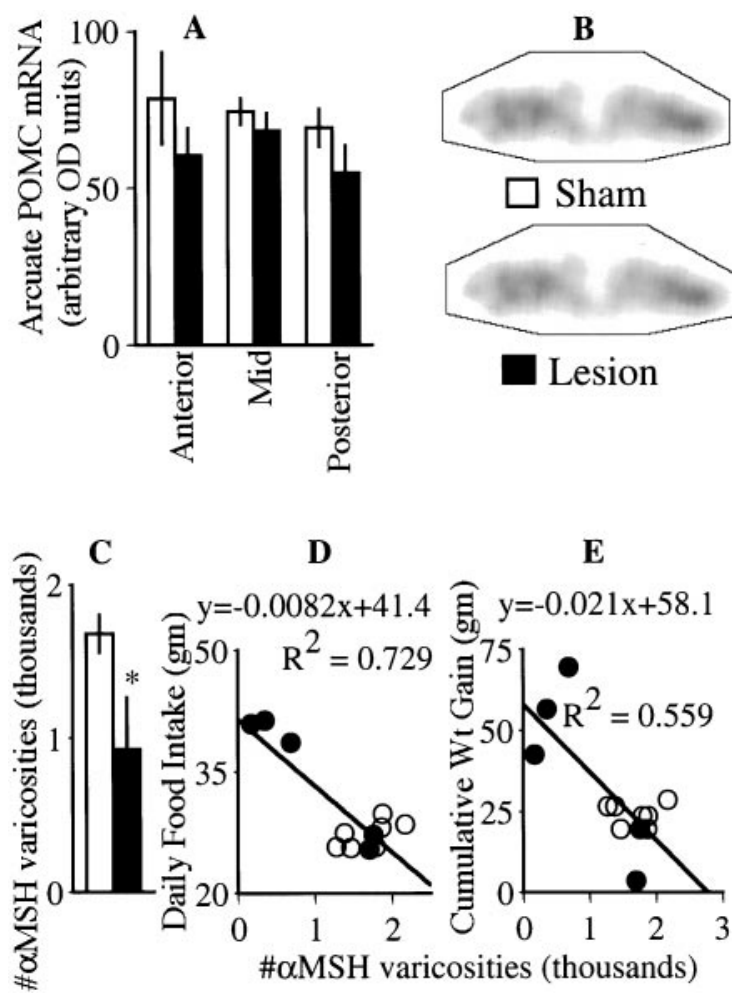

Figure 7. $\quad$ PVN $\alpha \mathrm{MSH}$ and body energy balance. $A$, POMC mRNA was similar in sham $(n=10)$ and lesioned rats $(n=7)$ at all levels of the ARC that were analyzed. Each region (anterior, mid, posterior) is represented by the mean value from two sections per brain. $B$, Representative POMC autoradiographs of ARC in a sham and a lesioned rat in anterior ARC, both outlined by the template used in the analysis. $C$, The number of $\alpha \mathrm{MSH}$-positive varicosities in the PVN was decreased significantly in lesioned animals $(n=5)$ as compared with shams $(n=7 ; p=0.037)$. $D$, Food intake $(p=0.0004)$ and weight gain $(E ; p=0.005)$ were highly correlated to the number of $\alpha \mathrm{MSH}$-immunostained varicosities in the PVN in lesioned and sham rats. Open symbols, Sham rats; filled symbols, lesioned rats.

At high magnification $\alpha \mathrm{MSH}$-positive fibers and varicosities were prominent in the PVN of the sham rat but rare in lesioned rats. Staining for $\alpha \mathrm{MSH}$ was reduced significantly in the PVN of lesioned animals $(n=5)$ as compared with shams $(n=7 ; p=0.04$; Figs. 6, 7C). Food intake $\left(r^{2}=0.729 ; p=0.0004\right)$ and weight gain $\left(r^{2}=0.56 ; p=0.005\right)$ were related strongly and negatively to $\alpha \mathrm{MSH}$ immunostaining in the PVN (Fig. 7D,E). In the remaining available tissue NPY immunostaining in the PVN also was reduced significantly in lesioned animals $(n=4)$ as compared with shams $(n=3 ; p=0.05$; Figs. $8,9 C)$ but was not related to food intake $\left(r^{2}=0.099 ; p=0.45\right)$ or weight gain $\left(r^{2}=0.069 ; p=\right.$ 0.53; Fig. $9 D, E)$.

CRF mRNA levels in the PVN were decreased significantly in lesioned $(n=9)$ rats as compared with shams $(n=6 ; p=0.028$; Fig. 10). Decreased levels were particularly apparent in the first two sections that were examined in the PVN (bregma -1.8 and bregma -1.9); differences in CRF expression in the posterior two sections of the nucleus were not individually significant. POMC mRNA levels were not decreased significantly ( $p=0.16$; see Fig. $7 A, B)$ in $\mathrm{ARC}$ of lesioned rats. However, the POMC mRNA in the posterior aspect of the ARC (bregma -3.8) was decreased to a greater extent than the middle (bregma -3.3) or anterior (bregma -2.4) levels. NPY mRNA levels were decreased significantly $(p=0.006$; see Fig. $9 A, B)$ in the ARC of lesioned animals as compared with shams. The decrease in NPY transcript was fairly uniform throughout the three anterior-to-posterior areas of the nucleus that were examined.

\section{DISCUSSION}

Horizontal knife cuts between the PVN and ARC increase food intake, body weight, adiposity, and plasma leptin levels within $7 \mathrm{~d}$ 

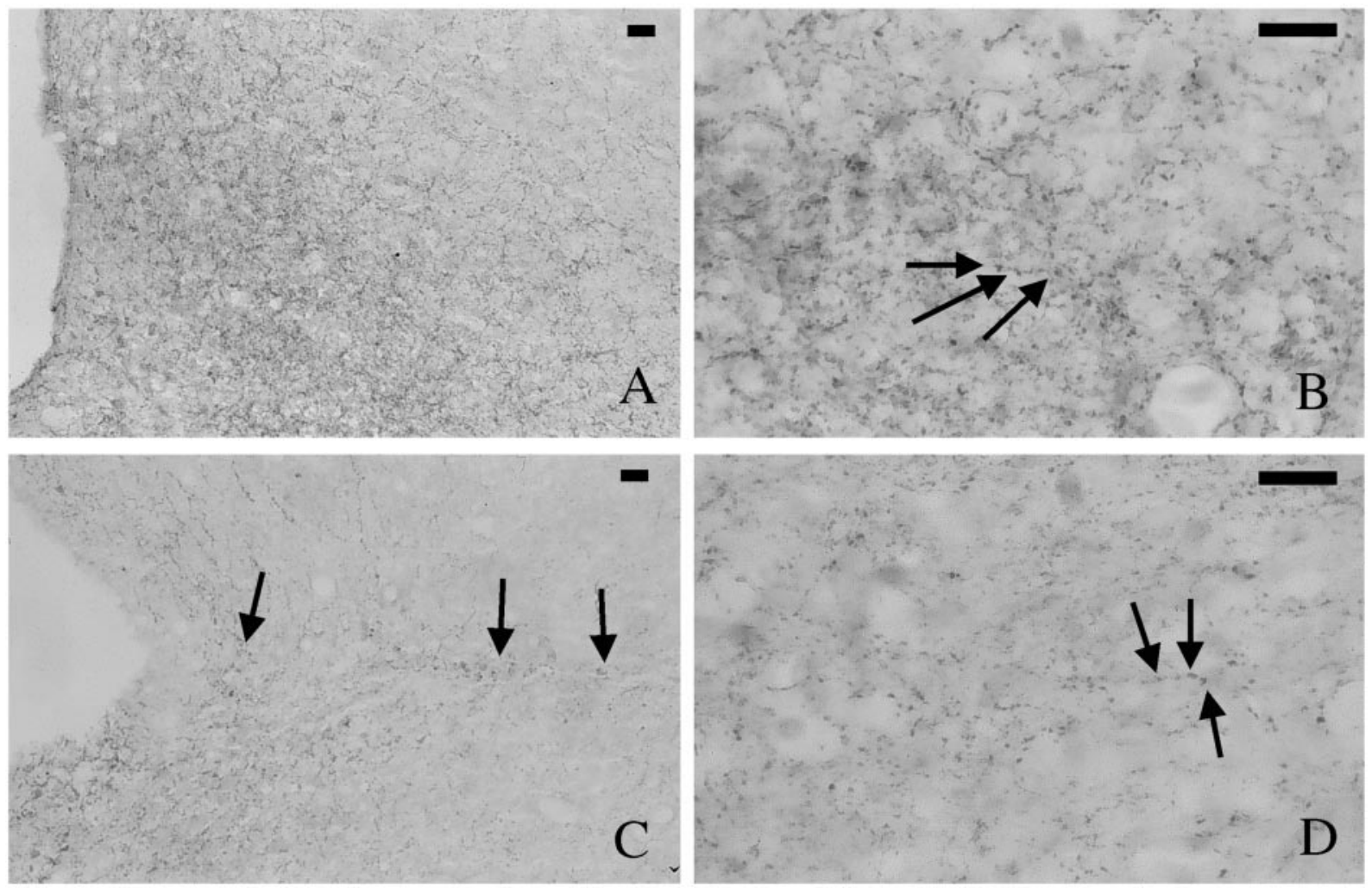

Figure 8. Immunostaining for NPY in the ventral hypothalamus. Top, Sham rat; bottom, lesioned rat. $A$, $C$, Arcuate nuclei, $200 \times$. NPY immunostaining was optimized for varicosity visualization. NPY-positive varicosities were found in both ARC and PVN and in web-like lines and linear shapes between the nuclei in sham rats. In lesioned rats NPY-positive varicosities were present in a higher concentration immediately ventral to the lesion $(C$, arrows $) . B, D, \mathrm{PVN}, 630 \times$. NPY-positive fibers and varicosities were prominent in the PVN of both groups, with shams $(B)$ having higher NPY levels than lesioned rats $(D)$. The irregular high background is attributable to the clusters of NPY-positive varicosities above and below the plane of focus. Scale bar, $50 \mu \mathrm{m}$ in all panels.

of surgery. These increases in energy stores correlate well with the loss of $\alpha \mathrm{MSH}$ staining in the PVN. The results suggest strongly that $\alpha \mathrm{MSH}$ fibers, derived from ARC neurons, normally act to regulate energy intake negatively. When the innervation of PVN from ARC is disrupted, rats overeat and become obese. Transection of the area between ARC and PVN also alters regulation of function in the HPA axis. Decreases in PVN $\alpha \mathrm{MSH}$ and NPY are associated with reduced CRF mRNA in PVN, pituitary ACTH content, and $\mathrm{ACTH}$ responses to restraint but with increased basal ACTH, suggesting that ARC neuropeptides also may function normally to regulate HPA activity.

The development of obesity in animals with small transections between the ARC and PVN is similar to that seen in rats with colchicine disruption of either the ARC or PVN (Choi and Dallman, 1999; Choi et al., 1999). In all three cases the animals eat more food in both light and dark and lose less weight during the light as compared with shams. This contrasts with the effects of colchicine or electrolytic lesions of the VMN, after which rats eat more during the light but less during the dark as compared with shams (Suemaru et al., 1995; Choi et al., 1996). Rats with VMN lesions also exhibit metabolic obesity that is independent of food intake (Tokunaga et al., 1986; Parkinson and Weingarten, 1990), in contrast to the nutritionally dependent obesity seen in PVNlesioned and ARC-lesioned rats (Tokunaga et al., 1986; Choi and Dallman, 1999; Choi et al., 1999). On the basis of histology, feeding behavior, and caloric efficiency of the lesioned rats in this study, we are confident that the dorsal extent of our cut does not impinge on the VMN. Basal hypothalamic deafferentation with a longer knife blade results in increased food intake but not significantly increased body weight (Scott and Knigge, 1981), in contrast to the pattern of increased food intake and body weight gain that is seen in the lesioned animals here.

Lesioned rats in the current study metabolically resemble ARClesioned rats and PVN-lesioned animals that have been described previously (Choi and Dallman, 1999; Choi et al., 1999). The insulin/leptin relationship is disrupted in lesioned animals in the current study and in rats after ARC disruption by colchicine injections (Choi and Dallman, 1999). We believe this relationship represents relative sympathetic/parasympathetic drive to fat and pancreas, suggesting that normal ARC inputs to PVN are required for normal autonomic balance. In contrast, UCP levels tend to rise in lesioned rats and in rats after PVN colchicine injections. BAT UCP levels increase when intact rats are overfed because of sympathetic activation of BAT in response to excess calories (Ghorbani et al., 1997). Together, these results suggest that the hypothalamic cuts of the current study disrupt ARC/PVN interconnections that are critical for autonomic regulation of metabolism.

There is reciprocal innervation between ARC and PVN (Sawchenko and Swanson, 1983), and immunostaining of POMC products has been shown by Kiss et al. (1984) to decrease after medially placed knife cuts between ARC and PVN. Approximately $8 \%$ of the neurons that synthesize POMC and $20 \%$ of those that synthesize NPY in ARC innervate the PVN (Baker and Herkenham, 1995). The PVN receives significant NPY innervation from the brainstem (Sahu et al., 1988) as well as from the ARC, whereas PVN $\alpha \mathrm{MSH}$ appears to arise primarily from the ARC in rats (Jacobowitz and O'Donohoe, 1978; Bronstein et al., 1992). Because food intake and cumulative body weight gain are correlated negatively with $\alpha \mathrm{MSH}$ but are not correlated with NPY immunostaining in the PVN, $\alpha \mathrm{MSH}$ innervation of PVN ordinarily may keep food intake and metabolism in check. However, the resolution of our analysis does not take into account PVN subdivisions that may have variations in NPY regulated by brainstem afferents that are sensitive to energy balance. Our findings suggest that the obesity seen in ARC-lesioned and PVN-lesioned animals is attributable to the loss of ARC melanocortinergic inputs to the PVN.

However, the region between ARC and PVN that was severed by the lesion is not composed exclusively of fibers and also contains 

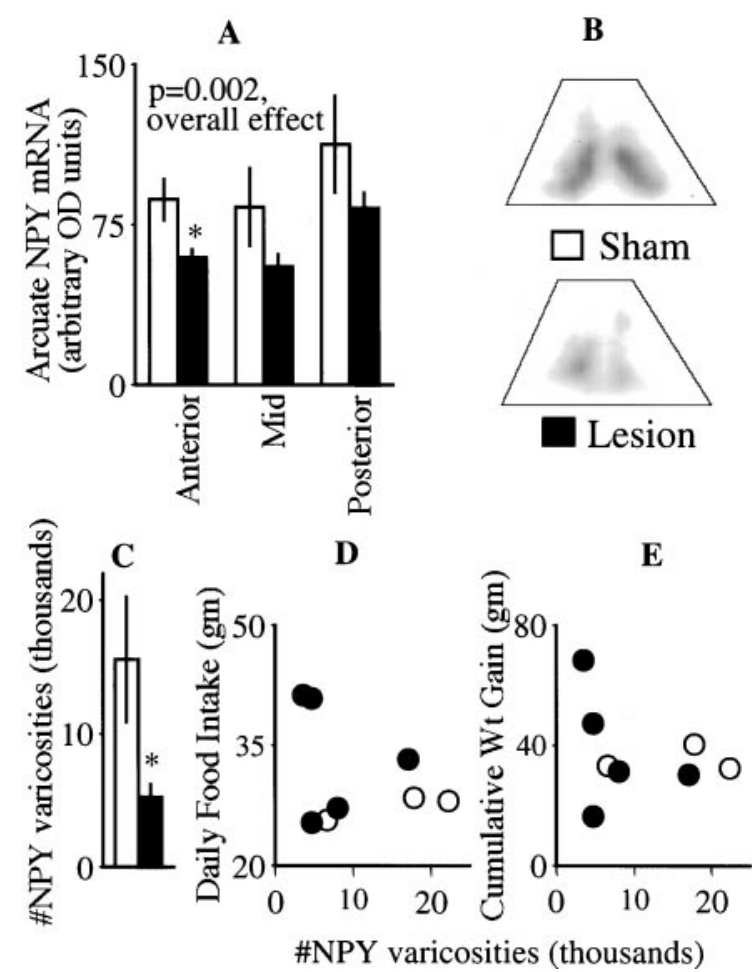

Figure 9. PVN NPY and body energy balance. $A$, NPY mRNA was decreased in lesioned rats $(n=10)$ as compared with shams $(n=7)$. $B$, Representative POMC autoradiographs of ARC in a sham and a lesioned rat in anterior ARC, both outlined by the template used in the analysis. $C$, The number of NPY-positive varicosities in the PVN was decreased significantly in lesioned animals $(n=5)$ as compared with shams $(n=3 ; p=$ $0.05)$. $D$, The number of NPY-stained varicosities in the PVN was not correlated significantly to food intake $\left(r^{2}=0.099\right)$ or $(E)$ to body weight gain $\left(r^{2}=0.069\right)$. Open symbols, Sham rats; filled symbols, lesioned rats.

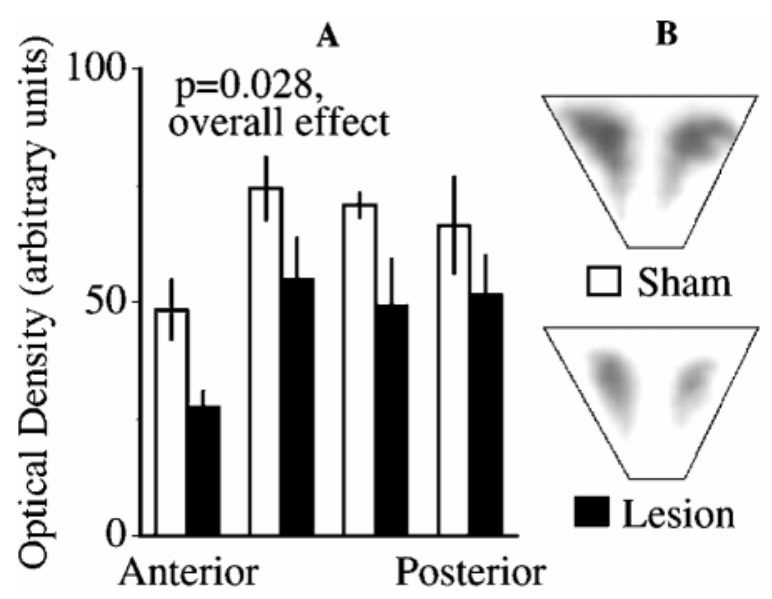

Figure 10. CRH mRNA in the PVN. $A$, There was an overall decrease in CRH mRNA in the PVN in lesioned $(n=6)$ rats as compared with shams $(n=9)$. The difference was greatest in the midanterior portion of the PVN. $B$, Representative autoradiographs from a sham and a lesioned rat in the mid-PVN, both outlined by the template used in analysis.

scattered neurons. It is possible that the consequences of our manipulations resulted in part from disruption of this cell-poor zone rather than entirely from disruption of input from PVN to ARC. Given the strong inverse relationship between $\alpha \mathrm{MSH}$ staining in PVN and energy balance, we suggest that the obesity that we observed derived primarily from removing ARC input to PVN.

Variations in food availability and metabolic demand are frequent stressors; thus it is not surprising that the HPA axis is involved intimately with body energy balance (Dallman et al., 1995). CRF infused into the PVN causes anorexia (Krahn and
Gosnell, 1988), and decreased food intake that occurs after restraint stress is blocked by infusion of a CRF antagonist (Smagin et al., 1999). Forced caloric loading increases PVN CRF transcript (Seeley et al., 1996), and spontaneous overfeeding significantly decreases plasma ACTH responses to acute restraint stress (Strack et al., 1997). Overnight fasting increases plasma ACTH and corticosterone but attenuates ACTH responses to restraint (Akana et al., 1994; Hanson et al., 1994; Dallman et al., 1999). Long-term food restriction to $85 \%$ of ad libitum-fed levels decreases PVN CRF; it also increases corticosterone and enhances the response to acute stress and to exogenous CRF (Garcia-Belenguer et al., 1993). From the above results, overfeeding appears to increase CRF expression whereas underfeeding decreases it.

Activity of the HPA axis in ARC/PVN-disconnected rats generally is decreased despite overfeeding that is exhibited by the rats. CRF transcript levels in the PVN, pituitary ACTH content, and plasma ACTH responses to restraint stress are all reduced in lesioned rats as compared with shams, although lesioned animals have higher basal plasma ACTH levels than shams. There are several mechanisms by which disruption of normal ACTH secretion could have occurred in lesioned animals. It is possible that cutting the axons coursing between the two nuclei caused retrograde damage and death of some of the parent cell bodies because the lesions decreased CRF and NPY and tended to decrease POMC expression. Alternatively, peptides normally transported to the PVN by ARC fibers (such as $\alpha \mathrm{MSH}$ and NPY) that act on CRF neurons are decreased in the PVN in lesioned animals, possibly resulting in decreased CRF expression. ARC efferents to other cell groups (VMN, DMN, and paraventricular nucleus of the thalamus) that, in turn, influence the PVN also may be disrupted by the cuts used in this study. Our lesions also probably disrupted the small number of fibers traveling in the midline from the medial $\mathrm{PVN}$ /periventricular hypothalamus to the median eminence, which could affect the regulation of ACTH secretagogues.

Similar patterns of plasma ACTH levels under basal and stress conditions also have been observed in rats after lesions of the ventromedial nuclei (Suemaru et al., 1995; Choi et al., 1996) and dorsomedial nuclei (S. J. Choi, personal communication) or after inhibition of DMN by muscimol injection (Stotz-Potter et al., 1996) and after PVN isolation (Levin et al., 1988). Those studies coupled with this suggest that the PVN may provide an inhibitory tone to basal plasma ACTH secretion but a positive drive to pituitary ACTH synthesis and plasma ACTH response to stress. Both "directions" appear to require a balanced input of ARC, DMN, and VMN to PVN CRF-containing motor neurons of the HPA axis. Alternatively, the close proximity to or involvement of the subparaventricular zone by the lesions may compromise circadian cues to the HPA axis and decrease the amplitude of plasma ACTH variations over $24 \mathrm{hr}$ (Choi et al., 1998).

There were no differences in plasma corticosterone between treatment groups. The disruption of PVN/ARC connections may alter the biological activity of ACTH secreted by the anterior pituitary (Castro and Morrison, 1997) or may reduce adrenal sensitivity to ACTH (Wilkinson et al., 1981), thus resulting in elevated basal ACTH with normal corticosterone. This is supported by the similarity of thymic weights between the two groups; the thymus is a corticosteroid target tissue and reflects well the preceding hormonal levels (Dallman et al., 1999). It is probable that differences in corticosterone responses to stress were not detected because of our sampling times. During early times after restraint (15 and $30 \mathrm{~min}$ ) ACTH values in both groups were high enough to saturate the adrenal corticosterone response (Kaneko et al., 1981), and no differences would be expected. Had we sampled at later times, the duration of the corticosterone response to restraint probably would have been curtailed in the lesioned as compared with the sham animals.

A frequently studied model of ARC lesions is neonatal exposure of rodents to monosodium glutamate (MSG), which results in lifelong obesity, hypogonadism, and sterility. MSG-treated rats have extensive histological damage and decreased glucocorticoid receptor in the ARC region, mild adrenal hypertrophy, and elevated plasma 
corticosterone (but not plasma ACTH) as compared with controls both before and after restraint stress (Olney, 1969; Margarinos et al., 1988; Larsen et al., 1994). The increased basal plasma ACTH (but not plasma B) in this study contrasts with that seen in MSG-treated rats, but both exhibit increased drive to the HPA axis. The fact that both lesions affect HPA responsivity underscores the importance of the ARC to the stress axis. However, MSG lesions are so extensive in duration and dimension that they cannot be compared directly with ARC/PVN disconnection when the effect of ARC on the HPA axis is addressed.

From these experiments it appears that the PVN is a critical relay of information from ARC for the control of body energy balance. Our results also show that the ARC has more than one role in regulating the HPA axis, both directly by supporting plasma ACTH responses to restraint stress and by acting as a relay for the DMN or the VMN in control of basal plasma ACTH levels.

\section{REFERENCES}

Akana SF, Strack AM, Hanson ES, Dallman MF (1994) Regulation of activity in the hypothalamo-pituitary-adrenal axis is integral to a larger hypothalamic system that determines caloric flow. Endocrinology 135:1125-1134.

Baker RA, Herkenham M (1995) Arcuate nucleus neurons that project to the hypothalamic paraventricular nucleus: neuropeptidergic identity and consequences of adrenalectomy on mRNA levels in the rat. J Comp Neurol 358:518-530.

Bronstein DM, Schafer MKH, Watson SJ, Akil H (1992) Evidence that $\beta$-endorphin is synthesized in cells in the nucleus tractus solitarius: detection of POMC mRNA. Brain Res 587:269-275.

Calogero AE, Gallucci WT, Gold PW, Chrousos GP (1988) Multiple feedback regulatory loops upon rat hypothalamic corticotropin-releasing hormone secretion: potential clinical implications. J Clin Invest 82:767-774.

Castro MG, Morrison E (1997) Post-translational processing of proopiomelanocortin in the pituitary and in the brain. Crit Rev Neurobiol 11:35-57.

Choi SJ, Dallman MF (1999) Hypothalamic obesity: multiple routes mediated by loss of function in medial cell groups. Endocrinol 140:4081-4088.

Choi SJ, Horsley C, Aguila S, Dallman MF (1996) The hypothalamic ventromedial nuclei couple activity in the hypothalamo-pituitaryadrenal axis to the morning fed or fasted state. J Neurosci 16:8170-8180.

Choi SJ, Wong LS, Yamat C, Dallman MF (1998) Hypothalamic ventromedial nuclei amplify circadian rhythms: do they contain a foodentrained endogenous oscillator? J Neurosci 18:3843-3852.

Choi SJ, Sparks R, Clay M, Dallman F (1999) Rats with hypothalamic obesity are insensitive to central leptin injections. Endocrinology 140:4426-4433.

Dallman MF, Akana SF, Strack AM, Hanson ES, Sebastian RJ (1995) The neural network that regulates energy balance is responsive to glucocorticoids and insulin and also regulates HPA axis responsivity at a site proximal to CRF neurons. Ann NY Acad Sci 771:730-742.

Dallman MF, Akana SF, Bhatnagar S, Bell ME, Choi S, Chu A, Horsley C, Levin N, Meijer O, Soriano LR, Strack AM, Viau V (1999) Starvation: early signals, sensors, and sequelae. Endocrinology 9:4015-4023.

Fan W, Boston BA, Kesterson RA, Hruby VJ, Cone RD (1997) Role of melanocortinergic neurons in feeding and the agouti obesity syndrome. Nature 385:165-168.

Garcia-Belenguer S, Oliver C, Mormede P (1993) Facilitation and feedback in the hypothalamo-pituitary-adrenal axis during food restriction in rats. J Neuroendocrinol 5:663-668.

Ghorbani M, Claus TH, Himms-Hagen J (1997) Hypertrophy of brown adipocytes in brown and white adipose tissues and reversal of dietinduced obesity in rats treated with a $\beta_{3}$-adrenoreceptor agonist. Biochem Pharmacol 54:121-131.

Hanson ES, Bradbury MJ, Akana SF, Scribner KS, Strack AM, Dallman MF (1994) The diurnal rhythm in adrenocorticotropic responses to restraint in adrenalectomized rats is determined by caloric intake. Endocrinology 134:2214-2220.

Huszar D, Lynch CA, Fairchild-Huntress V, Dunmore JH, Fang Q, Berkemeier LR, Gu W, Kesterson RA, Boston BA, Cone RD, Smith FJ, Campfield LA, Burn P, Lee F (1997) Targeted disruption of the melanocortin-4 receptor results in obesity in mice. Cell 88:131-141.

Jacobowitz DM, O’Donohoe TL (1978) $\alpha$-Melanocyte stimulating hormone: immunohistochemical identification and mapping in neurons of the rat brain. Proc Natl Acad Sci USA 75:6300-6304.

Kaneko M, Kaneko K, Shinsako J, Dallman MF (1981) Adrenal sensitivity to adrenocorticotropin varies diurnally. Endocrinology 109:70-75.

Kiss JZ, Cassell MD, Palkovits M (1984) Analysis of the ACTH/ $\beta$ endorphin $/ \alpha$-MSH immunoreactive afferent input to the hypothalamic paraventricular nucleus. Brain Res 324:91-99.

Krahn DD, Gosnell BA (1988) Behavioral effects of corticotropin- releasing factor: localization and characterization of central effects. Brain Res 443:63-69.

Larsen PJ Mikkelsen JD, Jessop D, Lightman SL, Chowdrey HS (1994) Neonatal monosodium glutamate treatment alters both the activity and the sensitivity of the rat hypothalamo-pituitary-adrenocortical axis. J Endocrinol 141:497-503.

Levin N, Shinsako J, Dallman MF (1988) Corticosterone acts on the brain to inhibit adrenalectomy-induced adrenocorticotropin secretion. Endocrinology 122:694-701.

Liposits Z, Sievers L, Paull WK (1987) Serotonin and neuropeptide-Y immunoreactive innervation of hypothalamic corticotropin-releasing factor (CRF) synthesizing neurons. J Histochem Cytochem 35:1029.

Margarinos AM, Estivarez F, Morado MI, De Nicola AF (1988) Regulation of the central nervous system-pituitary-adrenal axis in rats after neonatal treatment with monosodium glutamate. Neuroendocrinology 48:105-111.

McKibbin PE, Cotton SJ, McMillan S, Holloway B, Mayers R, McCarthy HD, Williams G (1991) Altered neuropeptide Y concentrations in specific hypothalamic regions of obese ( $f a / f a$ ) Zucker rats: possible relationship to obesity and neuroendocrine disturbances. Diabetes 40:1423-1429.

Murphy B, Nunes CN, Ronan JJ, Harper CM, Beall MJ, Hanaway M, Fairhurst AM, Van der Ploeg LHT, MacIntyre DE, Mellin TN (1998) Melanocortin-mediated inhibition of feeding behavior in rats. Neuropeptides 32:491-497.

Olney JW (1969) Brain lesions, obesity, and other disturbances in mice treated with monosodium glutamate. Science 164:719-721.

Parkinson WL, Weingarten HP (1990) Dissociative analysis of ventromedial hypothalamic obesity syndrome. Am J Physiol 259:R829-R835.

Sahu A, Kalra SP, Crowley WR, Kalra PS (1988) Evidence that NPYcontaining neurons in the brain stem project into selected hypothalamic nuclei: implication in feeding behavior. Brain Res 457:376-378.

Sanacora G, Kershaw M, Finkelstein JA, White JD (1990) Increased hypothalamic content of preproneuropeptide Y mRNA in genetically obese Zucker rats and its regulation by food deprivation. Endocrinology 127:730-737.

Sawchenko PE, Swanson LH (1983) The organization of forebrain afferents to the paraventricular and supraoptic nuclei of the rat. J Comp Neurol 218:121-144.

Scott PM, Knigge KM (1981) Immunocytochemistry of luteinizing hormone-releasing hormone, vasopressin, and corticotropin following deafferentation of the basal hypothalamus of the male rat brain. Cell Tissue Res 219:393-402.

Seeley RJ, Matson CA, Chavez M, Woods SC, Dallman MF, Schwartz MW (1996) Behavioral, endocrine, and hypothalamic responses to involuntary overfeeding. Am J Physiol 271:R819-R823.

Shalts E, Feng Y-J, Ferin M, Wardlaw SL (1992) $\alpha$-Melanocytestimulating hormone antagonizes the neuroendocrine effects of corticotropin-releasing factor and interleukin- $1 \alpha$ in the primate. Endocrinology 131:132-138.

Smagin GN, Howell LA, Redmann Jr S, Ryan DH, Harris RB (1999) Prevention of stress-induced weight loss by third ventricle CRF receptor antagonist. Am J Physiol 276:R1461-R1468.

Spina M, Merlo-Pich E, Chan RKW, Basso AM, Rivier J, Vale W, Koob GF (1996) Appetite-suppressing effects of urocortin, a CRF-related neuropeptide. Science 273:1561-1564.

Stanley BG, Magdalin W, Seirafi A, Ngyen MM, Leibowitz SF (1992) Evidence for neuropeptide Y mediation of eating produced by food deprivation for a variant of the Y1 receptor mediating this peptide's effect. Peptides 11:581-587.

Stotz-Potter EH, Morin SM, DiMicco JA (1996) Effect of muscimol into the dorsomedial or paraventricular hypothalamic nucleus on air stressinduced neuroendocrine and cardiovascular changes in rats. Brain Res 742:219-224.

Strack AM, Bradbury MJ, Dallman MF (1995) Corticosterone decreases nonshivering thermogenesis and increases lipid storage in brown adipose tissue. Am J Physiol 268:R183-R191.

Strack AM, Akana SF, Horsley CJ, Dallman MF (1997) A hypercaloric load induces thermogenesis but inhibits stress responses in the SNS and HPA system. Am J Physiol 272:R840-R848.

Suemaru S, Darlington DN, Akana SF, Cascio CS, Dallman MF (1995) Ventromedial hypothalamic lesions inhibit corticosteroid feedback regulation of basal ACTH during the trough of the circadian rhythm. Neuroendocrinology 61:453-463.

Tokunaga K, Fukushima M, Kemnitz JW, Bray GA (1986) Comparison of ventromedial and paraventricular lesions in rats that become obese. Am J Physiol 251:R1221-R1227.

Wahlestedt C, Skagerberg G, Ekman R, Heilig M, Sundler F, Hakanson R (1987) Neuropeptide Y (NPY) in the area of the hypothalamic paraventricular nucleus activates the pituitary-adrenocortical axis in the rat. Brain Res 417:33-38.

Wilkinson C, Shinsako J, Dallman MF (1981) Return of pituitary adrenal function after adrenal enucleation or transplantation: diurnal rhythms and responses to ether. Endocrinology 109:162-167. 